9. Suchyta, M.R., Peters, J.I. \& Black, R.D. Case report: Chronic Acinetobacter calcoaceticus var. antitratus pneumonia. Am J Med Sci 1987, 294(2): 117-119.

10. Vathesatogkit, P., Charoenphan, P., Saenghirunvattana, S., Kiatboonsri, S. \& Sathapatayavongs, B. Communityacquired Acinetobacter pneumonia in Thailand: report of 5 cases. J Med Assoc Thai 1987, 70: 96-101.

11. Westh, J. \& Terp, J. Community-acquired bacteraemic Acinetobacter calcoaceticus var. anitratus pneumonia. Infection 1988, 16: 303-304.

12. Barnes, D.J., Naraqi, S. \& Igo, J.D. Community-acquired Acinetobacter pneumonia in adults in Papua New Guinea. Rev Infect Dis 1988, 10: 636-639.

13. Krisanapan, S., Naphathorn, P. \& Kaewprom, $P$. Community-acquired Acinetobacter pneumonia: report of two cases. Southeast Asian J Trop Med Public Health 1989, 20(3): 497-498.
14. Gottlieb, T. \& Barnes, D.J. Community-acquired Acinetobacter pneumonia. Aust NZ J Med 1989, 19: 259-260.

15. Cunha, A.B., Klimwk, J.J., Gracewski, J., McLaughlin, J.C. \& Quintaliani, R. A common outbreak of Acinetobacter pulmonary infections traced to Wright respirometers. Postgrad Med J 1980, 56: 69-72.

16. Murray, B. \& Moellering, R.C. Aminoglycoside-modifying enzymes among clinical isolates of Acinetobacter calcoaceticus subsp. anitratus (Herella Vaginicola): explanation for high level aminoglycoside resistance. Antimicrob Agents Chemother 1979, 15: 190-199.

\title{
Chronic hypothermia and water intoxication associated with a neurodegenerative disease
}

\author{
E.L. Corbett, S. Sisodiya and D. Sarkar
}

Department of Medicine, Whittington Hospital, Highgate Hill, London N19 5NF, UK

\begin{abstract}
Summary: We describe a 71 year old man with a neurodegenerative condition who developed chronic inappropriate antidiuretic hormone secretion and hypothermia resulting in recurrent episodes of impaired consciousness. This combination of abnormalities is attributable to hypothalamic disease and has not to our knowledge been previously reported with clearly documented antidiuretic hormone excess.
\end{abstract}

\section{Introduction}

Chronic hypothermia of neurological origin is a rare condition that has been described in association with a number of different diseases, some of which can also cause the syndrome of inappropriate antidiuretic hormone (ADH) secretion. ${ }^{1-6}$ We report a case of chronic hypothermia and concurrent hyponatraemia in a patient with a neurodegenerative condition. $\mathrm{He}$ had required several previous admissions because of a confusional state due to acute exacerbations of hypothermia and hyponatraemia, and on followup remained hypothermic and hyponatraemic with inappropriately high ADH levels.

\section{Case history}

A 71 year old man was admitted as an emergency in March 1992 with a 3 day history of increasing

Correspondence: E.L. Corbett, M.B., B.Chir., M.R.C.P. Accepted: 17 May 1993 confusion and somnolence. He was disabled and lived with his able-bodied brother in a well-heated adapted flat.

He had congenital deformity of both feet with short Achilles tendons. There was a history of progressive neurological impairment, starting with pyramidal weakness in the legs first noted at the age of 44 years. Asymptomatic optic atrophy was also present at that time. Spastic tetraparesis, cerebellar ataxia and a sensorimotor peripheral neuropathy were apparent by the age of 55 years, when nerve conduction studies and biopsy showed chronic peripheral demyelination. A full myelogram was normal, as was cerebrospinal fluid analysis, although electrophoresis was not done. Vitamin $B_{12}$ was normal and syphilis serology was negative. There was a family history of congenital foot deformity. No firm diagnosis was made but at that time the condition was felt most likely to be a hereditary spinocerebellar degeneration.

Examination on this admission showed him to be somnolent and cold, with a rectal temperature of 
$32^{\circ} \mathrm{C}$. Neurological examination was compatible with the previous findings. He had pressure sores and an indwelling urinary catheter in place. There was a sinus bradycardia of 48 beats/minute and the blood pressure was $138 / 92 \mathrm{mmHg}$ with no postural drop. He had pitting oedema to the knees and of the sacral area. The jugular venous pressure was impossible to assess because of the extent of his deformities.

Investigations showed hyponatraemia and hyposmolality (Table I). Urine osmolality was inappropriately high and there was a high concentration of sodium in the urine. Other results were potassium $4.4 \mathrm{mmol} / \mathrm{l}$, creatinine $36 \mu \mathrm{mol} / 1$, total protein $76 \mathrm{~g} / \mathrm{l}$, albumin $37 \mathrm{~g} / \mathrm{l}$, urate $0.19 \mathrm{mmol} / 1$. Thyroid stimulating hormone, free thyroxine, adrenocorticotrophic hormone, short Synacthen test, serum angiotensin converting enzyme, prolactin and a porphyrin screen were normal. Recumbant renin and aldosterone levels from the fourth day of admission are shown in Table I. There was no obvious precipitating cause for his acute illness. In particular, there was no indication of acute infection on chest X-ray or blood cultures, although a catheter stream urine and swabs from his pressure sores grew mixed organisms. His brother confirmed that their flat had been warm over the previous few days and that our patient had not been drinking more fluids than usual.

Computerized tomography of the head showed cerebellar and cerebral atrophy (Figure 1). Magnetic resonance imaging was precluded by his contraction deformities.

Fluid restriction to $750 \mathrm{ml} /$ day and passive rewarming led to a marked clinical improvement

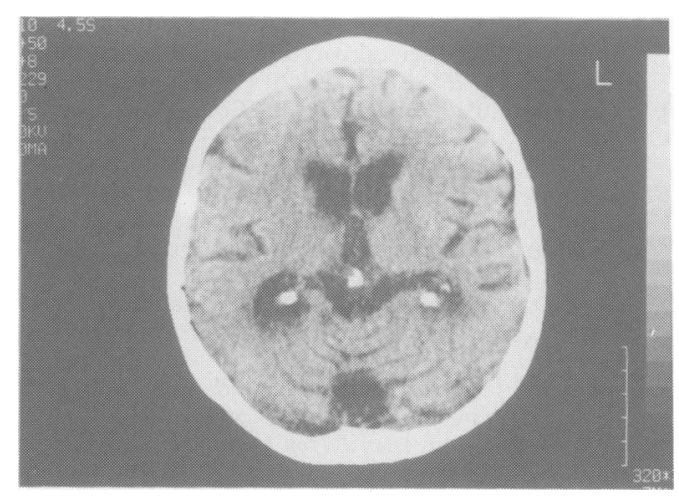

Figure 1 Computerized tomography of the head showing cerebellar and cerebral atrophy.

and complete resolution of his oedema within 4 days, by which time the oral temperature was $36^{\circ} \mathrm{C}$ and the serum sodium $126 \mathrm{mmol} / \mathrm{l}$. He remained $ᄋ$ hyponatraemic and the urine remained inappropriately concentrated throughout the admission. His oral temperature fell below $36^{\circ} \mathrm{C}$ on several occasions (Table I).

This patient had required five other admissions to this hospital over the previous 4 years because of acute confusion. There was no seasonal pattern to the admissions and on each occasion he had beef found to be hyponatraemic (sodium 119-124 $\mathrm{mmol} / \mathrm{l}$ ) and hypothermic with rectal temperatures as low as $32^{\circ} \mathrm{C}$. Plasma and urinary osmolalities had been determined on one previous admission in February 1991 (Table I).

Table I Serial in-patient plasma and urinary sodium and osmolality values with renin, aldosterone and ADH levels. Lowest recorded temperature for that day also shown

\begin{tabular}{|c|c|c|c|c|c|c|}
\hline & \multicolumn{3}{|c|}{ March 1992 admission } & \multirow[b]{2}{*}{ Feb 1991} & \multirow[b]{2}{*}{ Aug 1992} & \multirow[b]{2}{*}{ Oct 1992} \\
\hline & Day 1 & Day 2 & Day 10 & & & \\
\hline $\begin{array}{l}\text { Plasma sodium } \\
(\mathrm{mmol} / \mathrm{l})\end{array}$ & 117 & 126 & 128 & 120 & 124 & 127 \\
\hline $\begin{array}{l}\text { Plasma osmolality } \\
\left(\mathrm{mmol} / \mathrm{kg} \mathrm{H}_{2} \mathrm{O}\right)\end{array}$ & 246 & 270 & 269 & 245 & 259 & 282 \\
\hline $\begin{array}{l}\text { Urine sodium } \\
(\mathrm{mmol} / \mathrm{l})\end{array}$ & 142 & - & 110 & - & 60 & 153 \\
\hline $\begin{array}{l}\text { Urine osmolality } \\
\left(\mathrm{mmol} / \mathrm{kg} \mathrm{H}_{2} \mathrm{O}\right)\end{array}$ & 538 & 745 & 403 & 486 & 780 & 841 \\
\hline $\begin{array}{l}\text { Lowest temperature } \\
\left({ }^{\circ} \mathrm{C}\right)\end{array}$ & 32.0 & 36.0 & 35.0 & 32.5 & 35.5 & 35 \\
\hline $\begin{array}{l}\text { Plasma renin* } \\
\quad\left(\mathrm{pmol} / \mathrm{l}, \mathrm{NR}^{\dagger} 1.1-2.7\right)\end{array}$ & & 1.28 & & & & \\
\hline $\begin{array}{l}\text { Plasma aldosterone* } \\
\quad\left(\mathrm{pmol} / \mathrm{l}, \mathrm{NR}^{\dagger} 110-450\right)\end{array}$ & & 89 & & & & \\
\hline $\begin{array}{l}\text { Plasma ADH } \\
(\mathrm{pmol} / 1)^{\ddagger}\end{array}$ & & & & & 1.93 & 5.15 \\
\hline
\end{tabular}

${ }^{*}$ Renin and aldosterone measured at 9 a.m. with the patient recumbent overnight. ${ }^{\dagger}$ Normal range. ${ }^{\ddagger}$ Both values above
the normal range for the respective osmolalities..$^{7,8}$ 
Following the admission in March 1992 our patient required readmission on two occasions, in August and October, for management of his pressure sores. He was alert and clinically euvolaemic on both occasions. Random early morning paired serum and urinary osmolalities were taken (Table I). In both cases the ADH levels are inappropriately high for the serum osmolality. ${ }^{7,8}$ On both admissions his oral temperature was as low as $35^{\circ} \mathrm{C}$ with no complaints of feeling cold. He declined further investigation of his neurological condition or osmoregulation and temperature control.

\section{Discussion}

Our patient has had six admissions to this hospital because of confusion caused by simultaneous hypothermia and hyponatraemia. We have shown that the cause for our patient's hyponatraemia on the last of these admissions was inappropriate ADH secretion which persisted together with mild hypothermia over several months of follow up. The features of inappropriate ADH secretion in this patient were hyponatraemia with simultaneously high urinary osmolalities and urinary sodium concentrations. Two paired samples showed inappropriately high $\mathrm{ADH}$ levels for the respective osmolality. Renal, adrenal and thyroid function were normal and, although there was transient pitting oedema, the normal renin and suppressed aldosterone levels argue against cardiac failure, an important distinction as cardiac failure is a potent non-osmotic stimulus for ADH release. Hypothermia can cause oedema due to capillary leakage ${ }^{9}$ and the oedema did resolve on rewarming.

In this case our patient's neurodegenerative condition is the most likely cause of his chronic inappropriate $\mathrm{ADH}$ secretion. The syndrome of inappropriate $\mathrm{ADH}$ has been reported in association with various neurological conditions. ${ }^{7}$ We have, however, found no explanation for the episodic decompensation from a generally welltolerated steady-state of mild hyponatraemia and hypothermia.

Three different patterns of inappropriate ADH secretion have been described together with an identical clinical picture with normal hormone levels thought to arise from renal hypersensitivity to ADH. ${ }^{7}$ Our patient has declined formal assessment of the relationship between his osmolality and $\mathrm{ADH}$ release but the limited data available are most compatible with a type A pattern, in which the release of ADH is essentially random and bears no relationship to the osmolality. Type B syndrome of inappropriate $\mathrm{ADH}$ (SIADH) is unlikely because in this form the normal ADH-osmolality curve is shifted to the left and so a cut-off point for ADH release still exists, albeit at a lower osmolality than normal. Our patient, however, still produced a concentrated urine with a high sodium concentration despite a serum osmolality of $246 \mathrm{mmol} / \mathrm{kg}$ $\mathrm{H}_{2} \mathrm{O}$. Type C SIADH results from a 'leakage' of $\mathrm{ADH}$ at low serum osmolalities with an otherwise normal ADH-osmolality curve and is excluded here by the inappropriately high ADH level of $5.15 \mathrm{pmol} / \mathrm{l}$ with a low-normal osmolality of $282 \mathrm{mmol} / \mathrm{kg} \mathrm{H}_{2} \mathrm{O}$.

Hypothermia with core temperatures as low as $32^{\circ} \mathrm{C}$ was present on each of the acute admissions for confusion. Impaired consciousness can in itself cause hypothermia due to reduced ability to generate and conserve heat, but in this case hypothermia persisted after initial rewarming and as such indicates a central defect in thermoregulation.

Chronic hypothermia has been reported in patients with generalized neurological disease such as multiple sclerosis, ${ }^{1}$ Wernicke's encephalopathy, ${ }^{2}$ sarcoidosis, ${ }^{3}$ and following trauma and subarachnoid haemorrhage. ${ }^{4,5}$ Agenesis of the corpus callosum, with or without other developmental defects, can give rise to an episodic hypothermia (Shapiro's syndrome) notable for profuse sweating and vasodilatation at the start of each episode. More localized disease, such as gliosis, ${ }^{6}$ has been associated with chronic hypothermia; the lesion being in the region of the hypothalamus in all reported cases. Animal studies also point to the hypothalamus as the site of central thermoregulatory areas. ${ }^{10}$

Hypothermia with hyponatraemia thought to be due to the syndrome of inappropriate ADH has been reported previously in two patients. ${ }^{1,2}$ However, the published information is not sufficient to make a firm diagnosis in either case. The case report by Sullivan et al. ${ }^{1}$ concerns hypothermia in two patients with multiple sclerosis, one of whom was also hyponatraemic with a serum sodium of $107 \mathrm{mmol} / \mathrm{l}$. This latter patient is stated as having features compatible with SIADH but, as this was not the main concern of the report, neither the relevant urinary values nor the hydration status are provided. Haak et al. describe a patient with Wernicke's syndrome ${ }^{2}$ who became hypothermic and hyponatraemic during the course of a severe illness that included an aspiration pneumonia. This patient had been given frusemide prior to the onset of hyponatraemia, making interpretation of urinary and serum sodiums, and the diagnosis of SIADH unreliable. Finally Nussey et al..$^{5}$ have described a patient with a combination of chronic hypothermia and an osmoreceptor defect with disordered ADH release following a subarachnoid haemorrhage. This patient's main clinical problem was hypernatraemia, which was shown to be due to a combination of inadequate fluid intake and diabetes insipidus. His ADH levels were low des- 
pite consistently high serum osmolality, but he maintained an intact ADH response to nausea and hypoglycaemia, implicating impaired osmoreceptor function as the cause of his diabetes insipidus.

Both hypothermia and the SIADH are rare manifestations of neurological disease. The centres controlling thermoregulation and serum osmolality are both located within the hypothalamus. ${ }^{8,10}$ The organosum vasculosum of the lamina terminalis is thought to be the site of osmoreceptors, and the cells synthesizing ADH are located in the supraoptic and paraventricular nuclei. The pathways controlling thermoregulation are less well understood, but neurons that are responsive to temperature variation have been identified in the $\overrightarrow{\vec{\rho}}$ anterior hypothalamus and preoptic area. Al- $\overline{0}$ though we have no direct evidence, it is likely that $\frac{}{0}$ hypothalamic dysfunction in these areas is the $\overline{\bar{\rho}}$ cause of our patient's chronic hypothermia and $\mathbb{D}$ SIADH.

\section{References}

1. Sullivan, F., Hutchinson, M., Bahandeka, S. \& Moore, R.E. Chronic hypothermia in multiple sclerosis. J Neurol Neurosurg Psychiatry 1987, 50: 813-815.

2. Haak, H.R., van Hilten, J.J., Roos, R.A.C. \& Meinders, A.E. Functional hypothalamic derangement in a case of Wernicke's encephalopathy. Neth J Med 1990, 36: 291-296.

3. Lipton, J.M., Kirkpatrick, J. \& Rosenberg, R.N. Hypothermia and persisting capacity to develop fever. Occurence in a patient with sarcoidosis of the central nervous system. Arch Neurol 1977, 34: 498-504.

4. Ratcliffe, B.J., Bell, J.I., Collins, K.J., Frackowiak, R.S. \& Rudge, P. Late onset post-traumatic hypothermia. J Neurol Neurosurg Psychiatry 1983, 46: 72-74.

5. Nussey, S.S., Ang, V.T. \& Jenkins, J.S. Chronic hypernatraemia and hypothermia following subarachnoid haemorrhage. Postgrad Med J 1986, 62: 467-471.

6. Fox, R.H., Davies, T.W., Marsh, F.P. \& Urich, H. Hypothermia in a young man with an anterior hypothalamic lesion. Lancet 1970, 2: 185-188.

7. Bayliss, R.H. \& Thompson, C.J. Osmoregulation of vaso- 3 pressin secretion and thirst in health and disease. Clin Endocrinol 1988, 29: 549-576.

8. Lightman, S. Central nervous system control of fluid balance: $\infty$ physiology and pathology. Acta Neurochirurgica Suppl 1990, $\vec{\infty}$ 47: $90-94$.

9. Reuler, J.B. Hypothermia: pathophysiology, clinical setting and management. Ann Intern Med 1978, 89: 519-527.

10. Mitchell, D. \& Laburn, H.P. Pathophysiology of temperature regulation. Physiologist 1985, 28: 507-517.

\section{Spontaneous coronary artery dissection: a report of three cases and review of the literature}

\section{Peter Kearney, Harsh Singh², John Hutter ${ }^{2}$, Saleem Khan, Gary Lee and James Lucey ${ }^{1}$}

Department of Cardiology, University College Cork, South Infirmary Hospital, and ${ }^{1}$ Bon Secours Hospital, Cork, Ireland, and ${ }^{2}$ Bristol Royal Infirmary, Bristol, UK

Summary: We describe the clinical course of three patients who developed spontaneous coronary artery dissection. All patients were young women, one 9 weeks pregnant. All presented with chest pain; one died suddenly proving refractory to resuscitation, another developed unstable angina culminating in myocardial infarction, cardiogenic shock and death, and the third patient underwent coronary artery bypass grafting following diagnosis of a spontaneous coronary dissection of the left anterior descending artery at angiography. Pathological findings in the two fatal cases are reported.

This condition, although rare, is a prominent cause of ischaemic coronary events in young women, when it is frequently associated with pregnancy or the puerperium. Most patients die suddenly, but a clinical spectrum is seen including stable and unstable angina, myocardial infarction and cardiogenic shock. The left anterior descending artery is most frequently affected. The classical histological finding is that of a large haematoma occupying the outer third of the media resulting in complete compression of the true lumen.

The cause of spontaneous dissection remains unclear but theories of aetiology include a medial eosinophilic angiitis, pregnancy-induced degeneration of collagen in conjunction with the stresses of parturition, and rupture of the vasa vasorum. 